\title{
ANALISIS KOMUNIKASI TENTANG FAKTOR-FAKTOR YANG MEMPENGARUHI KINERJA UKM PENYAMAKAN KULIT DI SUKAREGANG KABUPATEN GARUT
}

\author{
Fitrin Rawati Suganda, Erik Kartiko \\ Program Studi Manajemen, Universitas Garut \\ Jl. Raya Samarang No. 52A Tarogong Kidul, Garut, 44151 \\ No HP: 082216751807, 082130876695 \\ e-mail: fitrinrawati@uniga.ac.id, erikkartiko@uniga.ac.id
}

Naskah diterima tanggal 4 September 2020 direvisi tanggal 25 Maret 2021 disetujui tanggal 1 April 2021

\begin{abstract}
Abstrak
Sentra penyamakan kulit yang terletak di Sukaregang Kabupaten Garut didominasi Usaha Kecil dan Menengah (UKM). Dari 282 unit usaha tersebut, hanya 53 unit usaha dengan kategori kinerja yang baik, dengan indikator utama jumlah produksi yang dihasilkan setiap periodenya. Tujuan penelitian ini adalah untuk mengetahui dan menganalisis faktor-faktor yang mempengaruhi kinerja dan faktor yang paling dominan yang mempengaruhi kinerja UKM penyamakan kulit di Sukaregang Kabupaten Garut. Jumlah responden sebanyak 53 orang, dengan jumlah variabel awal adalah 30 variabel. Pengambilan sampel dengan teknik Purposive Sampling. Sedangkan metode analisis data menggunakan Uji Validitas, Uji Reliabilitas, dan Analisis Faktor Ekploratori. Berdasarkan uji kelayakan instrumen penelitian, hasilnya data valid dan reliabel. Berdasakan hasil Analisis Faktor dari 30 variabel awal, sebanyak 26 variabel yang memenuhi untuk proses analisis faktor selanjutnya, kemudian dari 26 variabel yang dianalisis tersebut terbentuk menjadi delapan faktor yang mempengaruhi kinerja UKM penyamakan kulit di Sukaregang Kabupaten Garut. Kedelapan Faktor tersebut diberi nama berdasarkan pertimbangan-pertimbangan tertentu, kedelapan faktor tersebut adalah: Faktor Skala Usaha, Faktor Proses Produksi, Faktor Unsur Produksi, Faktor Kinerja Karyawan, Faktor Eksternal, Faktor Entrepreneurship, Faktor Sumber Daya Manusia, Faktor Rantai Pasokan. Sedangkan faktor yang paling dominan yang mempengaruhi kinerja UKM penyamakan kulit di Sukaregang Kabupaten Garut adalah Faktor Unsur Produksi. Secara teoritis, hasil penelitian ini diharapkan dapat menjadi rujukan bagi penelitian berikutnya. Sedangkan secara praktis dapat memberikan informasi dan rekomendasi bagi para pelaku industri penyamakan kulit khususnya yang kinerja usahanya belum begitu bagus agar dapat memperhatikan dan menerapkan faktor-faktor yang dapat meningkatkan kinerja usahanya.
\end{abstract}

Kata-kata kunci: Analisis komunikasi; factor produksi; kinerja usaha; usaha kecil; usaha menengah

\begin{abstract}
The tannery center located in Sukaregang, Garut Regency, is dominated by Small and Medium Enterprises (SMEs). Of the 282 business units, only 53 business units have a good performance category, with the main indicator being the number of products produced in each period. The purpose of this study was to determine and analyze the factors that influence the performance and the most dominant factors that affect the performance of the leather tanning SMEs in Sukaregang, Garut Regency. The number of respondents was 53 people, with the number of first variables, was 30 variables. Sampling with purposive sampling technique. Meanwhile, the data analysis method used a validity test, reliability test, and exploratory factor analysis. Based on the feasibility test of the research instrument, the results are valid and reliable data. Based on the results of the Factor Analysis of the first 30 variables,. 26 variables were fulfilled for the next factor analysis process, then the 26 analyzed variables were formed into eight factors that influenced the performance of the leather tanning SMEs in Sukaregang, Garut Regency. The eight factors are named based on certain considerations, the eight factors are: business Scale Factor, Production Process Factor, Production Element Factors,
\end{abstract}


Employee Performance Factors, External Factors, Entrepreneurship Factors, Human Resources Factors, Supply Chain Factors. While the most dominant factor affecting the performance of the leather tanning SMEs in Sukaregang, Garut Regency is the Production Element Factor. Theoretically, the results of this study are expected to be a reference for further research. While practically it can give information and recommendations for the leather tanneries, especially those whose business performance is not so good, so they can pay attention to and apply factors that can improve their business performance.

Keywords: Communication analysis; production factor; business performance; small business; medium-sized businesses

\section{Pendahuluan}

Kabupaten Garut memiliki sentra industri penyamakan kulit di kampung Sukaregang. Industri ini, mengolah kulit mentah menjadi kulit tersamak yang merupakan bahan baku bagi industri kerajinan kulit. Industri penyamakan kulit ini masih didominasi oleh usaha kecil dan menengah (UKM). Untuk dapat menunjang sektor ekonomi nasional secara umum dan sektor ekonomi Kabupaten Garut secara khusus, diperlukan kinerja yang baik dari usaha penyamakan kulit. Peran keuangan, keterampilan manajemen, faktor lingkungan makro, dan infrastruktur merupakan elemen penting untuk kinerja UKM.

Sebagian besar para pelaku penyamakan kulit masih menggunakan mesin atau alat produksi yang masih sederhana sehingga produktivitas yang dihasilkan rendah, pada akhirnya produk yang dihasilkan tidak mampu bersaing. Permasalahan lainnya adalah terkait modal, banyak pelaku penyamakan kulit tidak memiliki modal untuk melakukan investasi, baik untuk bangunan pabrik/ruang manufaktur maupun mesinmesin yang digunakan untuk memproduksi kulit mentah menjadi kulit tersamak.

Dari jumlah 387 UKM penyamakan kulit menurut data tahun 2014, kemudian update data 2019 jumlah UKM penyamakan kulit hanya tinggal 282 unit usaha yang tersisa, salah satu penyebab hal ini karena para pelaku UKM tidak dapat mempertahankan kinerja usahanya. Dari periode ke periode kinerja usahanya mengalami penurunan, dengan indikator utama, yaitu penurunan dalam jumlah hasil produksi, yang pada akhirnya mereka harus gulung tikar. Dari 282 unit usaha penyamakan kulit di Sukaregang Kabupaten Garut, hanya 53 unit usaha dengan kategori kinerja yang baik, dengan indikator utama jumlah produksi kulit tersamak yang dihasilkan setiap periode nya (SATPEL Industri Perkulitan Garut, 2019). Kinerja dari 53 unit usaha penyamakan kulit tersebut terutama didukung oleh mesin-mesin yang mereka miliki dan juga sarana pabrik/ruang produksi.

Kinerja UKM penyamakan kulit di Sukaregang Kabupaten Garut telah menjadi kajian penelitian sebelumnya, diantaranya hasil penelitian Suganda, Katiko \& Muharam (2019), dari 100 responden pelaku penyamakan kulit di Sukaregang, menunjukkan bahwa tingkat kinerja UKM penyamakan kulit dalam kategori cukup tinggi, atau kinerja usahanya belum optimal. Kinerja usaha pada industri penyamak kulit ini, tentunya dipengaruhi oleh banyak faktor. Menurut Gemina, Silaningsih \& Yuningsih (2016) keberhasilan IKM sendiri sangat dipengaruhi oleh sumber daya manajerial atau dapat disebut sebagai kemampuan manajerial, investasi yang dilakukan 
perusahaan, karakteristik bisnis dan pemilik usaha atau pelaku usaha.

Sejalan dengan penelitian tersebut, yaitu menurut Nisar, Boateng, \& Wu (2018), hasil temuannya menunjukkan bahwa karakteristik perusahaan: ukuran dan sektor operasi, secara signifikan mempengaruhi kinerja UKM Norwegia. Kemudian menurut Irwin et al, (2018) hasil penelitiannya adalah human capital strategis memoderasi hubungan antara entrepreneurial orientation dan kinerja UKM di Amerika Serikat. Selanjutnya Seo \& Chae (2016) temuannya mengungkapkan bahwa tingkat keragaman perusahaan mempengaruhi jumlah kinerja yang dimanifestasikan oleh kegiatan inovatif UKM.

Sedangkan menurut Anggadwita \& Mustafid (2014) hasil penelitiannya menunjukkan bahwa faktor-faktor yang memiliki pengaruh positif yang signifikan terhadap kinerja UKM di Bandung yaitu aspek kewirausahaan, inovasi, kompetensi sumber daya manusia dan sustainability.

Dengan demikian untuk mencapai kinerja UKM melibatkan banyak faktor dalam pencapaiannya. Sehingga Perusahaan harus mampu mengetahui, menganalisis faktor mana yang dapat diterapkan untuk meningkatkan kinerja perusahaannya.

Berdasarkan pemaparan di atas, maka tujuan penelitian ini untuk mengetahui dan menganalisis faktor-faktor yang mempengaruhi kinerja dan faktor yang paling dominan yang mempengaruhi kinerja UKM penyamakan kulit di Sukaregang Kabupaten Garut. Sedangkan permasalahan yang dapat dirumuskan adalah sebagai berikut: Faktor-Faktor apa saja yang mempengaruhi kinerja UKM dan Faktor apa yang paling dominan yang mempengaruhi kinerja UKM penyamakan kulit di Sukaregang Kabupaten Garut?.

\section{Metode Penelitian}

Penelitian ini menggunakan jenis kuantitatif yang menekankan analsisnya pada data-data numerical (angka) yang diolah dengan metode statistika (Azwar, 2010). Metode dalam penelitin ini dengan pendekatan statistika multivariate interdepedensi, yang dilakukan dengan cara mengumpulkan data, menyusun data, mengolah data, dan menganalisis data yang diperoleh. Sedangkan data akan dianalisis dengan menggunakan analisis faktor ekploratori.

Populasi pada penelitian ini adalah UKM penyamaan kulit di Kabupaten Garut yang berjumlah 282 unit usaha. Teknik penarikan sampel yang digunakan adalah teknik Non-probability sampling dengan teknik purposive sampling. Jumlah sampel sebanyak 53 unit usaha penyamakan kulit dengan kategori kinerjanya sudah baik berdasarkan kinerja usaha tahun 2019, dengan indikator kinerja dilihat dari segi jumlah produksi per feet nya serta dari investasi nya. Sedangkan yang menjadi unit analisis adalah para pemilik atau manajer, karena pemilik atau manajer yang paling mengerti dengan faktor-faktor yang mempengaruhi kinerja UKM penyamakan kulit yang mereka kelola.

Teknik pengumpulan data dilakukan dengan studi dokumentasi yaitu dengan mencari dokumen-dokumen, laporan, literatur, publikasi, buku-buku serta beberapa hasil penelitian sejenis yang berkaitan dengan substansi penelitian. Selain itu studi lapangan, dengan melakukan observasi ke industri penyamakan kulit, wawancara dengan para pelaku bisnis penyamakan kulit, 
wawancara dengan kepala SATPEL Industri Perkulitan Garut, dan juga pengambilan data dengan menyebar kuesioner kepada 53 unit usaha penyamakan kulit di Sukaregang Kabupaten Garut.

Metode analisis data yang digunakan diantara uji validitas dan uji reliabilitas untuk kelayakan instrumen penelitian, kemudian analisis faktor eksploratori. Menurut Ghozali (2012) Exploratory Factor Analysis bertujuan untuk mencari pengelompokkan baru variabel asli menjadi variabel yang jumlahnya makin sedikit, atau kumpulan faktor-faktor yang lebih sedikit dari jumlah faktor yang sebelumnya atau awal sehingga hasilnya akan lebih mudah dikontrol. Teknik pengolahan dan analisis data dalam penelitian ini menggunakan bantuan software SPSS (Statistical Product and Service Solutions) versi 22.

\section{Hasil Penelitian dan Pembahasan}

Hasil uji kelayakan instrumen penelitan, yaitu berupa hasil uji validitas dan hasil uji Reliablitas seperti yang disajikan pada Tabel 1. Sedangkan hasil dari uji reliabilitas seperti yang disajikan pada Tabel 2.

Tabel 1

Hasil Uji Validitas

\begin{tabular}{|c|c|c|c|}
\hline Varibel & $\begin{array}{c}\text { Corrected Item- } \\
\text { Total Correlation/ (r hitung) } \\
\end{array}$ & $\begin{array}{c}\mathrm{r} \text { tabel } \\
(0,05 ; 51)\end{array}$ & Keputusan \\
\hline Varibel 1 & 0,344 & 0,2706 & Valid \\
\hline Varibel 2 & 0,339 & 0,2706 & Valid \\
\hline Varibel 3 & 0,563 & 0,2706 & Valid \\
\hline Varibel 4 & 0,458 & 0,2706 & Valid \\
\hline Varibel 5 & 0,484 & 0,2706 & Valid \\
\hline Varibel 6 & 0,632 & 0,2706 & Valid \\
\hline Varibel 7 & 0,449 & 0,2706 & Valid \\
\hline Varibel 8 & 0,403 & 0,2706 & Valid \\
\hline Varibel 9 & 0,356 & 0,2706 & Valid \\
\hline Varibel 10 & 0,510 & 0,2706 & Valid \\
\hline Varibel 11 & 0,421 & 0,2706 & Valid \\
\hline Varibel 12 & 0,403 & 0,2706 & Valid \\
\hline Varibel 13 & 0,322 & 0,2706 & Valid \\
\hline Varibel 14 & 0,271 & 0,2706 & Valid \\
\hline Varibel 15 & 0,356 & 0,2706 & Valid \\
\hline Varibel 16 & 0,279 & 0,2706 & Valid \\
\hline Varibel 17 & 0,328 & 0,2706 & Valid \\
\hline Varibel 18 & 0,544 & 0,2706 & Valid \\
\hline Varibel 19 & 0,282 & 0,2706 & Valid \\
\hline Varibel 20 & 0,564 & 0,2706 & Valid \\
\hline Varibel 21 & 0,309 & 0,2706 & Valid \\
\hline Varibel 22 & 0,295 & 0,2706 & Valid \\
\hline Varibel 23 & 0,332 & 0,2706 & Valid \\
\hline Varibel 24 & 0,358 & 0,2706 & Valid \\
\hline Varibel 25 & 0,303 & 0,2706 & Valid \\
\hline Varibel 26 & 0,318 & 0,2706 & Valid \\
\hline Varibel 27 & 0,331 & 0,2706 & Valid \\
\hline Varibel 28 & 0,330 & 0,2706 & Valid \\
\hline Varibel 29 & 0,294 & 0,2706 & Valid \\
\hline Varibel 30 & 0,315 & 0,2706 & Valid \\
\hline
\end{tabular}

Sumber: Hasil Pengolahan Data, 2020 
Jurnal Komunikasi Universitas Garut: Hasil Pemikiran dan Penelitian

Vol. 7, No. 1, April 2021

Halaman 635-648

Berdasarkan Tabel 1, hasil uji validitas dengan alpha 0,05 dan $\mathrm{df}=53-2$ serta menggunakan uji dua arah maka diketahui $r$ tabel sebesar 0,2706, sehingga ke 30 item pernyataan adalah valid karena nilai $r$ hitung $>r$ tabel.

Tabel 2

Hasil Uji Reliabilitas

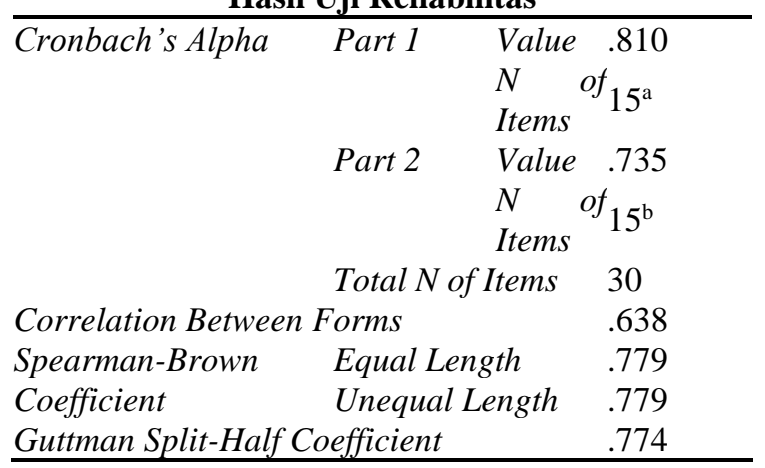

Sumber: Hasil Pengolahan Data, 2020
Berdasarkan Tabel 2, hasil uji reliabilitas diperoleh nilai Guttman SplitHalf Coefficient sebesar 0,774 > 0,2706 ( $\mathrm{r}$ tabel) maka keputusannya alat ukur dikatakan reliabel. Sehingga data layak untuk dianalisis lebih lanjut.

Untuk menganalisis faktor-faktor yang mempengaruhi kinerja UKM penyamakan kulit di Sukaregang Kabupaten Garut, peneliti menggunakan analisis faktor dengan bantuan software IBM SPSS 22. Berdasarkan hasil pengumpulan dan pengolahan data awal, telah dirangkum sebanyak 30 variabel yang mempengaruhi kinerja UKM penyamakan kulit di Sukaregang Kabupaten Garut. Variabel-variabel tersebut, seperti disajikan pada Tabel 3 di bawah ini.

Tabel 3

Variabel Penelitian

No. Variabel Penelitian

\begin{tabular}{llll}
\hline 1. & Ketersediaan Bahan Baku & 16. & Pengetahuan pemilik usaha \\
\hline 2. & Kualitas bahan baku & 17. & Usia Pemilik Usaha \\
\hline 3. & Harga bahan baku & 18 & Skala usaha \\
\hline 4. & Ketersediaan obat-obatan kimia & 19. & Keterampilan Karyawan \\
\hline 5. & Kualitas obat-obatan & 20. & Jumlah karyawan \\
\hline 6. & Harga obat-obatan kimia & 21. & Aturan kerja \\
\hline 7. & Ketersediaan mesin produksi & 22. & Motivasi kerja \\
\hline 8. & Ketepatan sistem sewa mesin produksi & 23. & Kemudahan mendapatkan akses kredit \\
\hline 9. & Ketepatan proses produksi & 24. & Modal kerja \\
\hline 10. & Cahaya matahari yang cukup & 25. & Kompensasi \\
\hline 11. & Lokasi Pabrik & 26. & Permintaan pasar \\
\hline 12. & Lahan produkai & 27. & Marketing/pemasaran \\
\hline 13. & Daya Dukung Lingkungan Sekitar & 28. & Peraturan Pemerintah \\
\hline 14. & Latar Belakang pendidikan pemilik usaha & 29. & Fasilitas Pemerintah \\
\hline 15. & Pengalaman pemilik usaha. & 30. & Ketersediaan air \\
\hline
\end{tabular}

Sumber: Hasil Pengumpulan Data, 2020

Analisis faktor ini diawali dengan uji Kaiser-Meyer-Olkin Measure of Sampling Adequacy (KMO-MSA), dengan asumsi atau persyaratan yang harus dipenuli adalah nilai KMO MSA harus lebih besar dari 0,5 dan nilai Barlett's test of Sphericity (Sig) lebih kecil dari 0,05, serta nilai Anti-Image correlation harus lebih besar dari 0,50 (Ghozali 2012). Tabel hasil uji KMO dan Barltlett's test of Sphericity disajikan pada Tabel 4 berikut ini. 
Jurnal Komunikasi Universitas Garut: Hasil Pemikiran dan Penelitian

Vol. 7, No. 1, April 2021

Halaman 635-648

Tabel 4

Hasil Uji KMO dan Barltlett's test of Sphericity

\begin{tabular}{lll}
\hline Kaiser-Meyer-Olkin Measure of Sampling Adequacy. & .550 \\
\hline Bartlett's Test of Sphericity & Approx. Chi-Square & 704.279 \\
\cline { 2 - 3 } & $d f$ & 435 \\
\cline { 2 - 3 } & Sig. & .000 \\
\hline
\end{tabular}

Sumber: Hasil Pengolahan Data, 2020

Berdasarkan pada Tabel 4, hasil uji dari 0,05 . Hal ini berarti analisis faktor KMO MSA sebesar 0,550 yaitu lebih besar dari 0,50. Sedangkan nilai Barlett's test of Sphericity (Sig) adalah 0,000 lebih kecil

dapat dilanjutkan. Selanjutnya hasil nilai Anti Image Correlation disajikan pada

Tabel 5

Hasil Anti Image Correlation

\begin{tabular}{cccccc}
\hline No & Varibel & $\begin{array}{c}\text { Anti Image } \\
\text { Correlation }\end{array}$ & No & Varibel & $\begin{array}{c}\text { Anti Image } \\
\text { Correlation }\end{array}$ \\
\hline 1. & $\mathrm{X} 1$ & 0,5 & 16. & $\mathrm{X} 16$ & 0,5 \\
\hline 2. & $\mathrm{X} 2$ & 0,6 & 17. & $\mathrm{X} 17$ & 0,4 \\
\hline 3. & $\mathrm{X} 3$ & 0,6 & 18. & $\mathrm{X} 18$ & 0,6 \\
\hline 4. & $\mathrm{X} 4$ & 0,4 & 19. & $\mathrm{X} 19$ & 0,5 \\
\hline 5. & $\mathrm{X} 5$ & 0,6 & 20. & $\mathrm{X} 20$ & 0,7 \\
\hline 6. & $\mathrm{X} 6$ & 0,7 & 21. & $\mathrm{X} 21$ & 0,7 \\
\hline 7. & $\mathrm{X} 7$ & 0,7 & 22. & $\mathrm{X} 22$ & 0,5 \\
\hline 8. & $\mathrm{X} 8$ & 0,6 & 23. & $\mathrm{X} 23$ & 0,5 \\
\hline 9. & $\mathrm{X} 9$ & 0,6 & 24. & $\mathrm{X} 24$ & 0,6 \\
\hline 10. & $\mathrm{X} 10$ & 0,7 & 25. & $\mathrm{X} 25$ & 0,6 \\
\hline 11. & $\mathrm{X} 11$ & 0,6 & 26. & $\mathrm{X} 26$ & 0,5 \\
\hline 12. & $\mathrm{X} 12$ & 0,6 & 27. & $\mathrm{X} 27$ & 0,4 \\
\hline 13. & $\mathrm{X} 13$ & 0,5 & 28. & $\mathrm{X} 28$ & 0,5 \\
\hline 14. & $\mathrm{X} 14$ & 0,4 & 29. & $\mathrm{X} 29$ & 0,5 \\
\hline 15. & $\mathrm{X} 15$ & 0,6 & 30. & $\mathrm{X} 30$ & 0,5 \\
\hline
\end{tabular}

Sumber: Hasil Pengolahan Data, 2020

Berdasarkan Tabel 5, hasil nilai Anti Image Correlation menunjukkan bahwa variabel dengan nilai korelasi lebih kecil dari 0,5 dikeluarkan dari analisis yaitu variabel X4, X14, X17, X 27. Selanjutnya dilakukan kembali langkah analisis faktor dengan variabel yang mempunyai nilai Anti Image Correlatin yang lebih dari 0,5 yaitu variabel X1, X2, X3, X5, X6, X7, X8, X9, X10, X11, $\mathrm{X} 12, \mathrm{X} 13, \mathrm{X} 15, \mathrm{X} 16, \mathrm{X} 18, \mathrm{X} 19, \mathrm{X} 20, \mathrm{X} 21$, X22, X23, X24, X25, X6, X28, X29, X30.

Kemudian dilakukan kembali uji Kaiser-Meyer-Olkin Measure of Sampling
Adequacy (KMO-MSA) seperti disajikan pada Tabel 6. 
Jurnal Komunikasi Universitas Garut: Hasil Pemikiran dan Penelitian

Vol. 7, No. 1, April 2021

Halaman 635-648

Tabel 6 Hasil Uji KMO dan Barltlett's test of Sphericity

\begin{tabular}{lll}
\hline Kaiser-Meyer-Olkin Measure of Sampling Adequacy. & .632 \\
\hline Bartlett's Test of Sphericity & Approx. Chi-Square & 550.267 \\
\cline { 2 - 3 } & df & 325 \\
\cline { 2 - 3 } & Sig. & .000 \\
\hline
\end{tabular}

Sumber: Hasil Pengolahan Data, 2020

Berdasarkan Tabel 6, hasil uji KMO signifikan pada 0,05. Jadi dapat disimpulkan memenuhi syarat yaitu di atas 0,5 , begitu juga bahwa analisis faktor dapat diteruskan. dengan Bartlett's Test of Sphericity juga

Tabel 7

Hasil Uji Total Variance Explained

\begin{tabular}{|c|c|c|c|c|c|c|c|c|c|}
\hline \multirow{2}{*}{$\begin{array}{c}\text { Com- } \\
\text { ponent }\end{array}$} & \multicolumn{3}{|c|}{ Initial Eigenvalues } & \multicolumn{3}{|c|}{$\begin{array}{c}\text { Extraction Sums of Squared } \\
\text { Loadings }\end{array}$} & \multicolumn{3}{|c|}{$\begin{array}{c}\text { Rotation Sums of Squared } \\
\text { Loadings }\end{array}$} \\
\hline & Total & $\begin{array}{c}\text { \% of } \\
\text { Variance }\end{array}$ & $\begin{array}{l}\text { Cumula- } \\
\text { tive \% }\end{array}$ & Total & $\begin{array}{c}\text { \%of } \\
\text { Variance }\end{array}$ & $\begin{array}{l}\text { Cumula- } \\
\text { tive } \%\end{array}$ & Total & $\begin{array}{c}\% \text { of } \\
\text { Variance }\end{array}$ & $\begin{array}{c}\text { Cumulati-ve } \\
\%\end{array}$ \\
\hline 1 & 5.669 & 21.806 & 21.806 & 5.669 & 21.806 & 21.806 & 3.177 & 12.221 & 12.221 \\
\hline 2 & 2.447 & 9.410 & 31.216 & 2.447 & 9.410 & 31.216 & 2.929 & 11.265 & 23.485 \\
\hline 3 & 2.046 & 7.868 & 39.083 & 2.046 & 7.868 & 39.083 & 2.318 & 8.917 & 32.402 \\
\hline 4 & 2.023 & 7.780 & 46.863 & 2.023 & 7.780 & 46.863 & 2.298 & 8.840 & 41.242 \\
\hline 5 & 1.724 & 6.631 & 53.494 & 1.724 & 6.631 & 53.494 & 2.082 & 8.009 & 49.251 \\
\hline 6 & 1.501 & 5.772 & 59.265 & 1.501 & 5.772 & 59.265 & 1.843 & 7.090 & 56.341 \\
\hline 7 & 1.233 & 4.742 & 64.007 & 1.233 & 4.742 & 64.007 & 1.631 & 6.274 & 62.616 \\
\hline 8 & 1.139 & 4.379 & 68.386 & 1.139 & 4.379 & 68.386 & 1.500 & 5.770 & 68.386 \\
\hline 9 & .989 & 3.803 & 72.189 & & & & & & \\
\hline 10 & .852 & 3.276 & 75.464 & & & & & & \\
\hline 11 & .806 & 3.099 & 78.564 & & & & & & \\
\hline 12 & .776 & 2.986 & 81.550 & & & & & & \\
\hline 13 & .679 & 2.610 & 84.160 & & & & & & \\
\hline 14 & .637 & 2.450 & 86.610 & & & & & & \\
\hline 15 & .606 & 2.330 & 88.940 & & & & & & \\
\hline 16 & .526 & 2.022 & 90.962 & & & & & & \\
\hline 17 & .406 & 1.560 & 92.522 & & & & & & \\
\hline 18 & .371 & 1.429 & 93.950 & & & & & & \\
\hline 19 & .328 & 1.262 & 95.212 & & & & & & \\
\hline 20 & .253 & .973 & 96.185 & & & & & & \\
\hline 21 & .243 & .934 & 97.119 & & & & & & \\
\hline 22 & .214 & .823 & 97.941 & & & & & & \\
\hline 23 & .192 & .738 & 98.680 & & & & & & \\
\hline 24 & .148 & .571 & 99.250 & & & & & & \\
\hline 25 & .129 & .495 & 99.745 & & & & & & \\
\hline 26 & .066 & .255 & 100.000 & & & & & & \\
\hline
\end{tabular}

Sumber: Hasil Pengolahan Data, 2020

Berdasarkan Tabel 7, nilai $\mathrm{r}$ (nilai eigen value $>1$ menjadi faktor). Faktor 1 mampu menjelaskan $21,80 \%$ variasi, Faktor 2 mampu menjelaskan 9,41\% variasi, Faktor 3 mampu menjelaskan 7,87\% variasi, Faktor 4 mampu menjelaskan $7,78 \%$ variasi, Faktor 5 mampu menjelaskan $6,63 \%$ variasi, Faktor
6 mampu menjelaskan 5,77\%, Faktor 7 mampu menjelaskan $4,74 \%$ variasi, dan Faktor 8 mampu menjelaskan 4,37\% variasi. Maka total kedelapan faktor dapat menjelaskan $21,80 \%+9,41 \%+7,87 \%+$ $7,78 \%+6,63 \%+5,77 \%+4,74 \%+4,37 \%$ $=68,37 \%$ dari variabilitas ke 26 faktor tersebut. 
Jurnal Komunikasi Universitas Garut: Hasil Pemikiran dan Penelitian

Vol. 7, No. 1, April 2021

Halaman 635-648

Tabel 8

Hasil Uji Rotated Component Matrix

\begin{tabular}{|c|c|c|c|c|c|c|c|c|}
\hline & \multicolumn{8}{|c|}{ Component } \\
\hline & 1 & 2 & 3 & 4 & 5 & 6 & 7 & 8 \\
\hline $\mathrm{X} 1$ & .276 & .229 & -.232 & .383 & .126 & -.149 & .301 & .481 \\
\hline $\mathrm{X} 2$ & -.029 & .076 & .693 & .352 & .278 & -.113 & -.163 & -.102 \\
\hline $\mathrm{X} 3$ & .202 & .456 & .681 & -.022 & .014 & .090 & .219 & .007 \\
\hline X5 & .269 & .606 & .317 & .028 & .083 & .064 & -.374 & -.151 \\
\hline X6 & .330 & .647 & .156 & .108 & .199 & .020 & .067 & .004 \\
\hline $\mathrm{X7}$ & .063 & .719 & -.066 & .163 & .000 & .265 & -.179 & .075 \\
\hline $\mathrm{X} 8$ & .005 & .787 & .007 & -.008 & .068 & .138 & .213 & .006 \\
\hline X9 & -.097 & .139 & .445 & -.048 & .435 & .265 & -.027 & .246 \\
\hline $\mathrm{X} 10$ & .350 & .179 & .295 & .302 & .371 & .058 & .293 & -.097 \\
\hline $\mathrm{X} 11$ & .642 & .329 & .036 & -.179 & .070 & -.037 & -.228 & .042 \\
\hline $\mathrm{X} 12$ & .622 & .356 & .242 & -.399 & .008 & -.103 & -.040 & .080 \\
\hline X13 & .160 & -.133 & .261 & -.002 & .648 & .184 & .280 & .095 \\
\hline $\mathrm{X} 15$ & .397 & .153 & -.078 & -.212 & .286 & .511 & .280 & -.012 \\
\hline $\mathrm{X} 16$ & .051 & .157 & -.080 & -.003 & -.039 & .823 & -.080 & .301 \\
\hline $\mathrm{X} 18$ & .850 & .037 & -.013 & .293 & .039 & .116 & .089 & .044 \\
\hline X19 & .217 & .075 & .246 & .139 & -.094 & -.058 & .685 & .248 \\
\hline $\mathrm{X} 20$ & .844 & .021 & .094 & .281 & .014 & .109 & .135 & .040 \\
\hline $\mathrm{X} 21$ & .109 & -.092 & .137 & .658 & .298 & .103 & .048 & -.006 \\
\hline $\mathrm{X} 22$ & .068 & .324 & .124 & .489 & -.375 & .174 & .027 & .132 \\
\hline $\mathrm{X} 23$ & -.003 & .242 & .224 & .317 & -.087 & .718 & -.033 & -.219 \\
\hline $\mathrm{X} 24$ & .398 & .108 & .140 & .334 & -.115 & -.015 & -.611 & .273 \\
\hline $\mathrm{X} 25$ & .076 & .133 & .103 & .723 & -.061 & -.023 & -.058 & .129 \\
\hline X26 & .037 & -.050 & .189 & .074 & .186 & .157 & .029 & .783 \\
\hline $\mathrm{X} 28$ & .209 & .341 & -.201 & -.031 & .584 & -.130 & -.104 & -.019 \\
\hline X29 & -.152 & .200 & .122 & .185 & .675 & -.145 & -.183 & .289 \\
\hline X30 & .163 & -.147 & .700 & .162 & -.070 & .003 & .139 & .366 \\
\hline
\end{tabular}

Sumber: Hasil Pengolahan Data, 2020

Berdasarkan Tabel 8 Hasil uji Varimax Rotated Component Matrix jelas terlihat bahwa berkelompok pada Faktor 1 adalah X11, X12, X18, X20, X24. Pengelompokan pada Faktor 2 adalah X5, X6, X7, X8. Pengelompokan pada Faktor 3 adalah X2, X3, X9, X30. Pengelompokan pada Faktor 4 adalah X21, X22, X25. Pengelompokan pada Faktor 5 adalah X10,
X13, X28, X29. Pengelompokan pada Faktor 6 adalah X15, X16, X23. Pengelompokan pada Faktor 7 adalah X19. Pengelompokan pada Faktor 8 adalah X1, X26. Dengan demikian ke 26 variabel direduksi menjadi 8 faktor seperti disajikan pada Tabel 9.

Tabel 9

Faktor Baru yang Terbentuk

\begin{tabular}{llc}
\hline $\begin{array}{c}\text { Faktor Baru yang } \\
\text { Terbentuk }\end{array}$ & \multicolumn{1}{c}{ Variabel } & Loading Faktor \\
\hline \multirow{3}{*}{ Faktor 1 } & Lokasi Pabrik & 0.642 \\
\cline { 2 - 3 } & Lahan produksi yang luas & 0,371 \\
\cline { 2 - 3 } & Skala Usaha & 0,850 \\
\cline { 2 - 3 } & Jumlah Karyawan & 0,844 \\
\cline { 2 - 3 } & Modal Kerja & 0,398 \\
\hline Faktor 2 & Kualitas obat-obatan & 0.606 \\
\hline
\end{tabular}


Jurnal Komunikasi Universitas Garut: Hasil Pemikiran dan Penelitian

Vol. 7, No. 1, April 2021

Halaman 635-648

\begin{tabular}{|c|c|c|}
\hline & Harga obat-obatan kimia & 0,647 \\
\hline & Ketersediaan mesin produksi & 0,719 \\
\hline & Ketepatan sistem sewa mesin produksi & 0.787 \\
\hline \multirow{4}{*}{ Faktor 3} & Kualitas bahan baku & 0,693 \\
\hline & Harga bahan baku & 0,681 \\
\hline & Ketepatan proses produksi & 0,445 \\
\hline & Ketersediaan air & 0,700 \\
\hline \multirow{3}{*}{ Faktor 4} & Aturan kerja & 0,658 \\
\hline & Motivasi kerja & 0,489 \\
\hline & Kompensasi & 0,718 \\
\hline \multirow{4}{*}{ Faktor 5} & Cahaya Matahari & 0.622 \\
\hline & Daya dukung lingkungan sekitar & 0,648 \\
\hline & Peraturan pemerintah & 0,584 \\
\hline & Fasilitas pemerintah & 0,675 \\
\hline \multirow{3}{*}{ Faktor 6} & Pengalaman pemilik usaha & 0,511 \\
\hline & Pengetahuan pemilik usaha & 0,823 \\
\hline & Kemudahan mendapatkan akses kredit & 0,723 \\
\hline Faktor 7 & Keterampilan karyawan & 0,685 \\
\hline \multirow{2}{*}{ Faktor 8} & Ketersediaan bahan baku & 0,481 \\
\hline & Permintaan pasar & 0,783 \\
\hline
\end{tabular}

Sumber: Hasil Pengolahan Data, 2020

Berdasarkan pada Tabel 9, setelah dihitung nilai loading factor terbesar ada pada Faktor 3 yaitu sebesar 2,519, sehingga Faktor ke 3 merupakan faktor yang paling dominan yang mempengaruhi kinerja UKM penyamakan kulit di Sukaregang Kabupaten Garut.

Berdasarkan hasil pengolahan data tersebut di atas, untuk menjawab rumusan permasalahan pertama yaitu: Faktor-faktor apa saja yang mempengaruhi kinerja UKM penyamakan kulit di Sukaregang Kabupaten Garut. Maka pembahasan penelitian mengacu pada Tabel 9. Berdasarkan pada Tabel 9, dari 26 variabel yang dianalisis terbentuk menjadi 8 faktor, kemudian faktor-faktor tersebut diberi nama dan disimpulan sebagai berikut:

\section{- Faktor 1}

Faktor 1 yang terbentuk dari variabel yang terdiri dari: lokasi pabrik, lahan produksi yang luas, skala usaha, jumlah karyawan, modal kerja, maka
Faktor 1 ini diberi nama berdasarkan nilai loading factor tertinggi dari variabel pembentuk, sehingga Faktor 1 diberi nama Faktor Skala Usaha

Menurut Astuti dalam Anggraini (2013) skala usaha adalah kemampuan perusahaan dalam mengelola usahaya dengan melihat berapa jumlah karyawan yang dipekerjakan dan berapa besar pendapatan yang diperoleh perusahaan dalam suatu periode akuntasi. Mengacu pada pengertian tersebut, penamaan ini tepat, karena variabel yang menyertainya yaitu cahaya matahari, jumlah karyawan, modal kerja merupakan unsur-unsur yang merupakan bagian dari skala usaha.

Menurut Utami (2018) hasil temuannya menunjukkan bahwa skala usaha berpengaruh positif dan signifikan terhadap keberhasilan kinerja usaha UKM, dengan kata lain semakin tinggi skala usaha, maka semakin tinggi pula 
keberhasilan kinerja UKM makanan khas Banyumas.

\section{- $\quad$ Faktor 2}

Faktor 2 yang terbentuk dari variabel yang terdiri dari: kualitas obatobatan kimia, harga obat-obatan kimia, ketersediaan mesin produksi, dan ketepatan sistem sewa mesin produksi, maka Faktor 2 ini diberi nama berdasarkan nilai tertinggi loading factor yaitu variabel yang berhubungan dengan proses produksi, yaitu ketersediaan mesin produksi, dan ketepatan sistem sewa mesin produksi, sehingga Fakor 2 diberi nama Faktor Proses Produksi

Menurut Assauri (2016) proses produksi merupakan suatu kegiatan yang melibatkan sumber daya manusia, material, serta peralatan untuk menghasilkan suatu produk yang adan manfaatnya. Faktor proses produksi berpengaruh terhadap kinerja perusahaan, hal ini sejalan dengan penelitian Suharta (2016) yang mengemukakan bahwa berdasarkan hasil data yang diperoleh oleh peneliti faktor proses produksi dan faktor produksi sangat berpengaruh dan mendorong keberhasilan usaha, karena suatu produk tidak terlepas dari proses produksi, dan apabila proses produksi nya dilakukan secara efektif dan efesien maka hasil produksi nya pun akan baik.

\section{- $\quad$ Faktor 3}

Faktor 3 yang terbentuk dari variabel yang terdiri dari: kualitas bahan baku, harga bahan baku, ketepatan proses produksi, dan ketersediaan air. Faktor 3 ini diberi nama berdasarkan variabel-variabel pembentuk Faktor 3 yang mengacu pada bahan dan peralatan yang dibutuhkan dalam proses produksi, sehingga Fakor 3 diberi nama Faktor Unsur Produksi.
Unsur produksi merupakan semua sumber daya yang diperlukan dalam melakukan kegiatan produksi. Faktor produksi dapat mendorong kinerja perusahaan hal ini, hal ini sejalan dengan penelitian Ramanathan et al. (2012) hasil kami menunjukkan bahwa aspek operasi dan pemasaran dari e-commerce memiliki dampak kuat pada kinerja UKM di Taiwan. - Faktor 4

Faktor 4 yang terbentuk dari variabel yang terdiri dari: aturan kerja, motivasi kerja dan kompensasi. Faktor 4 ini diberi nama berdasarkan variabelvariabel pembentuk Faktor 4 yang mengacu pada unsur yang membentuk kinerja karyawan, sehingga Fakor 4 diberi nama Faktor Kinerja Karyawan.

Kinerja karyawan mempengaruhi keberhasilan kinerja perusahan, hal ini sejalan dengan hasil penelitian Vosloban (2012) yang menyatakan bahwa kinerja karyawan berkontribusi secara signifikan terhadap peningkatan kinerja perusahaan dalam perspektif manajerial dari berbagai perusahaan yang berbeda di Bucharest.

\section{- Faktor 5}

Faktor 5 yang terbentuk dari variabel yang terdiri dari: cahaya matahari yang cukup, daya dukung lingkungan sekitar, peraturan pemerintah, dan fasilitas pemerintah. Faktor 5 ini diberi nama berdasarkan variabel-variabel pembentuk Faktor 5 yang mengacu pada unsur- unsur eksternal perusahaan, sehingga Fakor 5 diberi nama Faktor Eksternal.

Menurut (Sandra, 2015) lingkungan eksternal merupakan keadaan yang berpengaruh dari luar perusahaan yang dapat mempengaruhi suatu perusahaan. Sedangkan menurut Pearce \& Robinson (2011) menjelaskan bahwa faktor eksternal mempengaruhi sebuah 
perusahaan dalam menentukan arah dan tindakan yang akan dilakukan perusahaan.

\section{- $\quad$ Faktor 6}

Faktor 6 yang terbentuk dari variabel yang terdiri dari: pengalaman pemilik usaha, pengetahuan pemilik usaha dan kemudahan mendapatkan akses kredit. Faktor 6 ini diberi nama berdasarkan variabel-variabel pembentuk Faktor 6 yang mengacu pada beberapa karakteristik entrpreneurship. Sehingga Faktor 6 ini dinamakan Faktor Entrepreneurship.

Menurut Kasmir

entrepreneurship merupakan kemampuan seorang pengusaha atau pemilik usaha didalam menciptakan sesuatu yang baru dan yang berbeda sehingga sesuatu tersebut memiliki nilai tambah. Pengertian ini bermaksud bahwa seorang entrepreneur adalah orang yang yang memiliki kemampuan dan pengalaman sebelumnya untuk menciptakan sesuatu yang belum pernah ada, selain itu kemudahan mendapatkan akses kredit mengacu pada kemampuan seorang entrepreneur dalam pengambilan resiko usaha.

Faktor entrepreneurship dapat mendorong keberhasilan usaha, hal ini sejalan dengan hasil penelitian (Dewi, 2013) yang mengemukakan bahwa entrepreneurship yang memiliki inovasi, kreatif, motivasi serta memiliki karakteristik sebagai pemilik usaha yang baik sangat mendorong keberhasilan usaha suatu perusahaan. Sejalan dengan penelitian tersebut yaitu Moorthy et al. (2012) kesimpulannya hasil penelitiannya menyatakan bahwa kewirausahaan yang efektif, manajemen sumber daya manusia yang tepat, penggunaan informasi pemasaran dan penerapan teknologi informasi memiliki dampak signifikan terhadap kinerja UKM di Malaysia.

\section{- $\quad$ Faktor 7}

Faktor 7 dibentuk oleh satu variabel yaitu keterampilan karyawan. Faktor 7 ini diberi nama berdasarkan variabel pembentuk Faktor 7 yang mengacu pada sumber daya manusia, sehingga Faktor 7 diberi nama Faktor Sumber Daya Manusia.

Menurut Sudarsana (2015) dalam penelitiannya menyatakan bahwa SDM (Sumber Daya Manusia) merupakan salah satu pondasi utama dan juga pondasi yang harus ada pada sebuah perusahaan. Faktor SDM dapat mempengaruhi kinerja usaha, hal ini sejalan dengan penelitian (Dewi, 2013; Nizar 2018) yang mengemukakan hasil penelitiannya bahwa faktor sumber daya manusia mendororng keberhasilan usaha. Menurutnya keberhasilan usaha dapat dilihat dari seberapa banyak sebuah usaha dapat memperkerjakan serta mempertahankan tenaga kerja yang berbakat serta terampil untuk mendukung tujuan perusahaan. Dimana tenaga kerja yang mahir akan memberikan kontribusi bagi perkembangan suatu usaha.

\section{- $\quad$ Faktor 8}

Faktor 8 yang terbentuk dari variabel yang terdiri dari: ketersediaan bahan baku dan permintaan pasar. Faktor 8 ini diberi nama berdasarkan variabelvariabel pembentuk, Faktor 8 yang mengacu pada rantai pasokan hulu dan hilir pada industri penyamakan kulit. Sehingga diberi nama Faktor Rantai Pasokan. Rantai hulu berupa jejaring perusahaan untuk memperoleh dan menjamin ketersediaan bahan baku, sedangkan rantai hilir merupakan jejaring perusahaan untuk memasarkan produk penyamakan kulit, yaitu untuk memenuhi permintaan pasar. 
Rantai pasokan menurut (Heizer dan Render, 2011), yaitu terdiri dari perusahaan yang mengambil bahan baku dari bumi/alam, perusahaan yang mentransformasikan bahan baku menjadi bahan setengah jadi atau komponen, supplier bahan-bahan pendukung produk, perusahaan perakitan, distributor, dan retailer yang menjual barang tersebut ke konsumen akhir.

Haryotejo dan Kusumawardhani (2015) hasil penelitiannya menunjukkan bahwa ketersediaan produk yang dimiliki oleh pemasok berpengaruh secara positif terhadap kinerja bisnis dengan asumsi faktor yang lainnya konstan. Sedangkna permintaan pasar mempengaruhi kinerja perusahaan, hal ini sejalan dengan penelitian Purwaningsi \& Kusuma (2015) hasil penelitiannya menunjukkan bahwa aspek internal perusahaan yang didalamnya termasuk aspek permintaan pasar mempengaruhi kinerja UKM di kota Semarang.

Sedangkan faktor yang paling dominan yang mempengaruhi kinerja UKM penyamakan kulit di Sukaregang Kabupaten Garut, dilihat dari jumlah loading faktor terbesar yaitu Faktor 3 yaitu Faktor Unsur Produksi.

\section{Kesimpulan}

Berdasarkan tujuan, hasil serta pembahasan dari penelitian, maka yang dapat disimpulkan dari penelitian ini adalah terdapat delapan faktor yang mempengaruhi kinerja UKM penyamakn kulit di Sukaregang Kabupaten Garut yaitu Faktor Skala Usaha, Faktor Proses Produksi, Faktor Unsur Produksi, Faktor Kinerja Karyawan, Faktor Ekternal, Faktor Entrepreneurship, Faktor Sumber Daya Manusia, Faktor Rantai Pasokan.
Sedangakan faktor yang paling dominan dari kedelapan faktor tersebut adalah Faktor Unsur Produksi.

Dengan demikian, diharapkan kepada para pelaku bisnis industri penyamakan kulit, dapat meningkatkan kinerja usahanya dengan memperhatikan dan menerapkan faktor-faktor yang dapat meningkatkan kinerja usaha tersebut. Instansi terkait yaitu SATPEL Industri perkulitan Garut yang mempunyai peranan strategis dalam mendorong pertumbuhan industri penyamakan kulit di Sukaregang Kabupaten Garut, diharapkan dapat menciptakan dan mengkomunikasikan strategi terbaik berdasarkan faktor-faktor yang mempengaruhi kinerja usaha penyamakan kulit, agar tidak hanya sebagian kecil unit usaha penyamakan kulit yang dapat meningkatkan kinerjanya, akan tetapi seluruh unit usaha penyamakan kulit di Sukaregang Kabupaten Garut dapat meningkatkan kinerjanya, sehingga industri penyamakan kulit dapat memiliki keunggulan bersaing dan menjadi salah satu industri andalan di Kabupaten Garut.

\section{Daftar Pustaka}

Anggadwita, G., \& Mustafid, Q. Y. (2014). Identification of Factors Influencing the Performance of Small Medium Enterprises (SMEs).

Procedia Social and Behavioral Sciences, 115, 415-423. doi:10.1016/j.sbspro.2014.02.448. Anggraeni, N. M. (2017). Analisis FaktorFaktor yang Mempengaruhi Keberhasilan Usaha Kecil dan Menengah Pada Pengrajin Tenun Songket di Desa Jinengdalem Kecamatan Buleleng. Nasional. Assaury, S. (2016). Manajemen Operasi Produksi (Pecapaian Sasaran 
Jurnal Komunikasi Universitas Garut: Hasil Pemikiran dan Penelitian

Vol. 7, No. 1, April 2021

Halaman 635-648

Organisasi Berkesinambungan). Jakarta: PT Raja Grafindo Persada. Azwar, Saifuddin. 2010. Metode Penelitian. Yogyakarta: Pustaka Pelajar. Santoso, S. (2015). Menguasai Statistik Multivariat. Jakarta: PT Elexmedia Komputindo.

Dewi, R. S. (2013). Pengaruh Faktor Modal Psikologis, Karakteristik, Inovasi, Manajemen Sumber Daya Manusia, dan Karakteristik UKM terhadap Perkembangan Usaha Pedagang Di Pasar Tradisional. Jurnal Administrasi Bisnis, 2(1). 29-40.

Gemina, D., Silaningsih, E., \& Yuningsih, E. (2016). Pengaruh Motivasi Usaha terhadap Keberhasilan Usaha dengan Kemampuan Usaha sebagai Variabel Mediasi pada IKM Makanan Ringan Periangan Timur Indonesia. Jurnal Manajemen Teknologi, 15(3), 297323. doi:

10.12695/jmt.2016.15.3.6.

Ghozali, I. (2012). Aplikasi Analisis Multivariate dengan Program IBM SPSS 23, Edisi 28. Semarang: Badan Penerbit Universitas Diponegoro.

Haryotejo, B., Kusumawardhani, A (2015), Analisis Pengaruh Kinerja Logistik pemasok terhadap Kinerja Bisnis (Studi pada Bengkel AHASS di Kota Semarang), Dipenogoro Journal of Management, 4(3), 2337-3792.

Heizer, Jay dan Barry Render. 2011. Operation Management. Tenth Edition. Pearson. New Jersey: Prentice Hall.
Irwin, K. C., Landay, K. M., Aaron, J. R., McDowell, W. C., Marino, L. D., \& Geho, P. R. (2018). Entrepreneurial Orientation (EO) and Human Resources Outsourcing (HRO): A "HERO" Combination for SME performance. Journal of Business Research, 90, 134-140. doi:10.1016/j.jbusres.2018.05.01.6

Kasmir. (2013). Kewirausahaan. Jakarta: Raja Grafindo Persada.

Moorthy, M., Tan, A., Choo, C., Chang, S., W., Yong Ping, J.T., Leong, T. K. (2012). A Study on Factors Affecting the Performance of SMEs in Malaysia. International Journal of Academic Research in Business and Social Sciences, 2(4), 224-239.

Nisar, S., Boateng, A., \& Wu, J. (2018). The Entry Mode Strategy and Performance of SMEs: Evidence from Norway. Research in International Business and Finance, $\quad 45, \quad 323-333$. doi:10.1016/j.ribaf.2017.07.164.

Nizar, M. (2015). Pengaruh Sumber Daya Manusia, Permodalan dan Pemasaran terhadap Kinerja Usaha Kecil dan Menengah Sari Apel Di Kecamatan Tutur. Iqtishoduna, 7(1).51-69.

Pearce, John A. dan Richard B. Robinson. 2011. Strategic Management Formulation, Implementation, and Control, Twelfth Edition, McGrawHill, New York.

Purwaningsih, R., \& Kusuma, P. Damar. (2015), Analisis Faktor-Faktor yang Mempengaruhi Kinerja Usaha Kecil dan Menengah (UKM) dengan Metode Structural Equation 
Jurnal Komunikasi Universitas Garut: Hasil Pemikiran dan Penelitian

Vol. 7, No. 1, April 2021

Halaman 635-648

Modelling (Studi Kasus UKM berbasis Industri Kreatif Kota Semarang). Prosiding SNST ke 6. Fakultas Teknik Universitas Wahid Hasyim Semarang.

Ramanathan, R., Ramanathan, U., \& Hsiao, H.-L. (2012). The Impact of E-Commerce on Taiwanese SMEs: Marketing and Operations Effects. International Journal of Production Economics, 140(2), 934-943. doi:10.1016/j.ijpe.2012.07.017.

Sandra, A. E. (2015). Pengaruh FaktorFaktor Eksternal dan Internal terhadap Kinerja Usaha Kecil dan Menengah di Jakarta. Bussiness Manajemen Jurnal, 11(1), 97-124.

Seo, Y. W., \& Chae, S. W. (2016). Market Dynamics and Innovation Management on Performance in SMEs: Multi-agent Simulation Approach. Procedia Computer Science, 91, 707-714. doi:10.1016/j.procs.2016.07.060.

Sudarsana, I, Ketut. (2015). Peningkatan Mutu Pendidikan Luar Sekolah dalam Upaya Pembangunan Sumber Daya Manusia. Jurnal Penjaminan Mutu, 1(1), 1-14.

Suganda, F. R., Kartiko, E., \& Muharam. (2019). Orientasi Wirausaha dan Network Capability dalam Upaya Peningkatan Kinerja pada IKM Penyamakan Kulit di Sukaregang Kabupaten Garut. Jurnal Wacana Ekonomi, 19(1), 1-12.

UPTD Industri Pangan, Olahan dan Kemasan Satuan Pelayanan Pengembangan Industri Perkulitan Garut Dinas Perindustrian dan Perdagangan Kabupaten Garut (2019).
Utami, T, Hastin (2018), Pengaruh Pengetahuan Pemilik, Skala Usaha, dan Umur Usaha terhadap Keberhasilan Kinerja Usaha dengan penggunaan Informasi Akuntansi sebagai Variabel Moderasi (Survei pada Pemilik Usaha UKM Makanan Khas di Kabupaten Banyumas), Jurnal Ekonomi Islam /Islamic Economics Journal, 6(1), 1-48.

Vosloban, R, Ioana (2012), The Influence of the Employee's Performance on the Company's Growth a Managerial Perspective, Emerging Market Queries in Finance and Business, 3, 660-665. 